\title{
Naloxone reverses ethanol's effects on sexual behavior of the female Syrian hamster
}

\author{
JEFFERY L. NELSON, NANCY L. OSTROWSKI, RALPH G. NOBLE, \\ and LARRY D. REID \\ Rensselaer Polytechnic Institute, Troy, New York 12181
}

\begin{abstract}
These studies evaluated the potential for naloxone to modify ethanol's suppression of sexual reflexes (lateral displacement) of the female golden hamster (Mesocricetus auratus). In Experiment 1 , sexual reflexes were reduced approximately $50 \%$ following ethanol administration $(1.2 \mathrm{~g} / \mathrm{kg}$, sc, in $10 \% \mathrm{v} / \mathrm{v})$. Naloxone $(4 \mathrm{mg} / \mathrm{kg}, \mathrm{sc})$ reversed ethanol's suppressive effect on sexual reflexes. The results from Experiment 2 indicated that naloxone $(.5,1.0,2.0$, and $8.0 \mathrm{mg} / \mathrm{kg}$ ) reversed ethanol's suppressive effect on lateral displacement in a dose-related manner. Naloxone $(8.0 \mathrm{mg} / \mathrm{kg})$, when administered alone, had no effects on sexual reflexes. Ethanol tended to increase lordosis latency and lordosis duration measures; however, these effects were not consistent across experiments. These observations lead to the suggestion that ethanol administration may modify female sexual behavior by activating, either directly or indirectly, the endogeneous opioid system.
\end{abstract}

Several lines of investigation have shown that ethanol will produce behavioral effects similar to those reported following opiate administration. Both morphine and ethanol facilitate pressing for direct electrical stimulation of the hypothalamus (ICSS). Recently it was reported that naloxone will reverse both morphine's and ethanol's facilitative effects (Lorens \& Sianti, 1979; Stapleton, Merriman, Coogle, Gelbard, \& Reid, 1979). Naloxone itself, however, will reduce pressing for brain stimulation (Belluzzi \& Stein, 1977; Stapleton et al., 1979). Consequently, it is difficult to separate naloxone's effects from its putative action on ethanol's effects.

Several other studies have shown that opiate antagonists counteract some of ethanol's effects. It has been reported that rhesus monkeys will self-administer ethanol (Altshuler, Phillips, \& Feinhandler, 1980). When the opiate antagonist, naltrexone, was administered, subsequent ethanol self-administration significantly decreased. These data lead to the suggestion that naltrexone decreases the reinforcing effects of ethanol by blocking the opiate receptors. Naloxone also reverses ethanol-induced comas in humans. It was reported that unconscious subjects in an ethanol-induced coma would react to stimuli and become conscious minutes after the administration of naloxone (Mackenzie, 1979; Sorensen \& Mattison, 1978). This report suggested a possible treatment value of opiate antagonists in ethanol treatment.

Recent research has shown that both morphine and ethanol have suppressant effects on measures of female sexual behaviors (Hetta, 1976; Ostrowski,

Research supported by NSF grant to R.G.N. N. L. Ostrowski is now at the Department of Psychology, University of Pittsburgh, Pittsburgh, Pennsylvania 15260.
Stapleton, Noble, \& Reid, 1979). When morphine is administered to rodents, several measures of female sexual behavior are inhibited. These inhibitory effects are reversed by opiate antagonists (Hetta, 1976; Ostrowski et al., 1979).

The following experiments were designed to determine whether naloxone would modify the suppressive effects of ethanol on the sexual behavior of the female golden hamster.

\section{EXPERIMENT 1}

Morphine, in relatively small doses, selectively decreases some aspects of female sexual performance in the golden hamster, an effect reversed by naloxone (Ostrowski et al., 1979). A preliminary study indicated that a dose of ethanol $(1.2 \mathrm{~g} / \mathrm{kg})$, which does not impair gross motor activity, suppresses some aspects of female sexual functioning. This experiment investigated naloxone's ability to antagonize the effects of ethanol on female sexual responses in the golden hamster.
Method
Subjects. The subjects were 45 adult, drug-naive, female golden hamsters (Mesocricetus auratus) weighing 90-100 $\mathrm{g}$ at the begin- ning of the procedures. The hamsters were purchased from Engle Laboratory Animals, Inc., Farmersburg, Indiana, at 90 days of age. They were housed in groups of four per cage in solid- bottom, plastic cages $(38 \times 33 \times 17 \mathrm{~cm})$ on corn-cob bedding (Sanicel). The animals were housed in a large colony room main- tained at $22^{\circ} \mathrm{C}$ on a reverse light-dark cycle (LD 14:10, with the dark phase beginning at $1400 \mathrm{~h}$ ). Standard laboratory food and tap water were always available. Females were ovariectomized under sodium pentobarbital anesthesia at least 1 week prior to testing. At the time of surgery, each subject was implanted sub- cutaneously (sc) with a Silastic-capped, 15-ga stainless steel hypo- dermic metal tube (1 cm in length) containing $17 \beta$-estradiol in crystalline form, which provided levels of circulating estradiol approximating those levels observed in proestrous females (Noble, 
1977). Sexually active male hamsters were used as stimulus males in all tests of sexual behavior.

Apparatus and Procedure. The experiment was conducted in two separate studies. The two studies were identical except that in the second study a single blind procedure was employed. In both studies, the subjects were randomly assigned (5-6 per group) to one of the following conditions: (1) ethanol administration $(1.2 \mathrm{~g} / \mathrm{kg}$ in $10 \%$ solution, $\mathrm{v} / \mathrm{v})$ followed by naloxone hydrochloride administration $(4 \mathrm{mg} / \mathrm{kg}$ of a $10-\mathrm{mg} / \mathrm{ml}$ solution), (2) ethanol administration followed by physiological saline administration $(1.0 \mathrm{ml} / \mathrm{kg}),(3)$ physiological saline administration $(15 \mathrm{ml} / \mathrm{kg})$ followed by naloxone hydrochloride administration, and (4) physiological saline administration followed by physiological saline administration. All injections were given subcutaneously (sc) under the loose skin of the upper back and neck. Sexual receptivity was induced by an injection of progesterone (.5 mg in $.1 \mathrm{ml}$ corn oil, sc) $4 \mathrm{~h}$ prior to testing (Noble, 1977). All testing was conducted between 1430 and $1730 \mathrm{~h}$ during the first $3 \mathrm{~h}$ of the dark phase of the light-dark cycle.

Each subject was tested for female sexual behavior immediately before and again $10 \mathrm{~min}$ after the first injection (ethanol or an equivalent volume of saline) and again 5 and 20 min after the second injection (naloxone or an equivalent volume of saline). All tests for female sexual behavior were conducted while the female was in a 5.5-gallon glass test chamber. During each test for female sexual behavior, the following measures were recorded: (1) the latency to the assumption of the lordosis posture (lordosis latency), (2) the duration of the lordosis response (lordosis duration), and (3) the magnitude of lateral displacement of the perivaginal region in response to tactile stimulation of the perineum (lateral displacement) (Noble, 1979).

The latency to assume lordosis was obtained by observing the time from when the female was placed in the test chamber with a sexually active male to the time she assumed the lordotic posture. Subjects not assuming lordosis within $180 \mathrm{sec}$ after the beginning of the first test were given no further testing. This procedure was repeated twice to generate an average lordosis latency score for each subject for each trial.

As soon as the female assumed lordosis, the male was removed. The experimenter then maintained the female's lordotic posture by manually stimulating ( $5 \mathrm{sec}$ in duration) her back and flank areas. The time between the end of manual stimulation and the end of the lordosis response, as indicated by the removal of a paw from the floor of the test chamber, was recorded as the lordosis duration. A consistent series of minor movements, such as movements of the head and arching of the back, are signs that the lordosis posture is going to be terminated. This procedure was repeated twice to obtain an average lordosis duration score for each animal per trial. Then the male was again placed in the test chamber just long enough to elicit lordosis in the female.

While in lordosis, female hamsters respond to stimulation of the perineal region in a characteristic manner. When light, tactile stimulation is applied within $1 \mathrm{~cm}$ of the vagina, the perineal region is turned in the direction of the stimulus (Noble, 1979). A set of Von Frey hairs (Semmes-Weinstein aesthesiometer force range 1.83 to $20.7 \mathrm{~g}$ in $4 \log$ unit steps) were used as the stimuli. Each stimulus was applied to four areas, the left outer zone $(.7 \mathrm{~cm}$ lateral to the midline), the left inner zone $(.2 \mathrm{~cm}$ lateral to the vagina), and the outer and inner zones on the right side. Each stimulus was applied in a pulsatile manner until the female's lateral movement stopped $(.5$ to $1 \mathrm{sec})$. The lateral displacement in millimeters was then recorded. The lordosis posture was maintained by stroking the female's back and flank areas during testing. Previous studies had indicated that the sum of the responses to each probe across sides is highly correlated with other measures of lateral displacement. Therefore, a single lateral displacement score was calculated for each trial for each subject. Table 1 provides a summary of the procedures.

\section{Results}

For each measure of sexual behavior (lordosis latency, lordosis duration, and lateral displacement), an analysis of variance (ANOVA) indicated that the factor associated with studies was not a reliable source of variance; nor were there any reliable study $\times$ drug interactions. Therefore, to summarize the data more simply, the data from the two studies were collapsed for further analysis.

Lordosis latency and lordosis duration. When the lordosis latency measures were submitted to an ANOVA, the only reliable effect was associated with the factor of ethanol injections $[F(1,41)=16.34$, $\mathrm{p}<.001$ ]. Ethanol-injected subjects exhibited a longer lordosis latency. The factor associated with naloxone was not a reliable source of variance $[F(1,41)=.19, \mathrm{p}<.67]$, and the ethanol $\times$ naloxone interaction was not significant. When the lordosis duration data were submitted to an ANOVA, the results indicated no significant reliable main effects or reliable interactions.

Lateral displacement. An ANOVA on the lateral displacement data confirmed that the inner-zone responses were reliably larger than outer-zone responses $[F(1,37)=100.91, p<.001]$, but the factor of zone did not interact with any other factor. Therefore, the lateral displacement measure was reduced to a single score-the sum of all responses (millimeters of displacement) across probes, zones, and side of stimulation.

Figure 1 depicts the effects of ethanol and naloxone on the lateral displacement measure for the four experimental conditions. As Figure 1 illustrates,

Table 1

Summary of Procedures

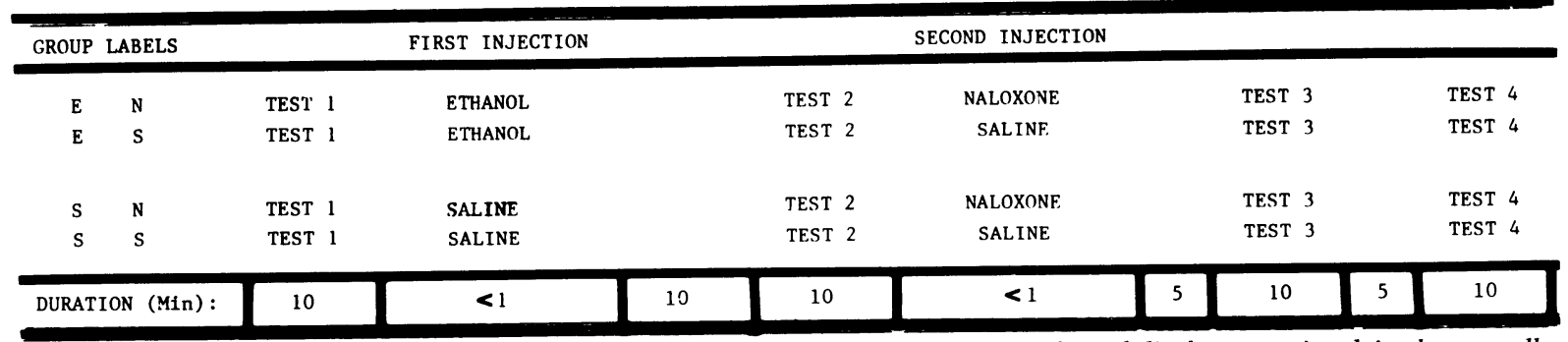

Note-Each test was a measure of (a) latency to lordosis, (b) lordosis duration, and (c) lateral displacement involving hormonally primed, sexually responsive female hamsters. 
ethanol reduced lateral displacement [ethanol $\times$ trials; $F(1,41)=29.45, p<.001]$. Naloxone reversed the effects of ethanol on lateral displacement (ethanol $\times$ naloxone $\times$ trials; $F(1,41)=5.42, p<.001]$. The interaction of naloxone $\times$ trials was not a reliable source of variance $[\mathrm{F}(1,41)=.05, \mathrm{p}<.83]$, suggesting that naloxone by itself had no significant effect on lateral displacement.

Post hoc comparisons (Newman-Keuls) indicated that those subjects receiving ethanol followed by saline showed a significant decline in lateral displacement over trials (ps $<.01$ ). Females receiving ethanol followed by naloxone showed a significant decline in lateral displacement following the ethanol injection $(p<.01)$. Twenty minutes after the naloxone injection, the lateral displacement scores of the subjects in the ethanol-naloxone group increased to preethanol levels and were significantly higher than postethanol lateral displacement scores $(\mathrm{p}<.01)$.

\section{Discussion}

The results of this experiment lead to the suggestion that ethanol suppresses some measures of female sexual behavior (lordosis latency and lateral displacement) while not affecting other measures of sexual behavior (lordosis duration). When naloxone was administered, ethanol's suppressive effect on lateral displacement was reversed. However, naloxone did not modify ethanol's effect on the lordosis latency.

\section{EXPERIMENT 2}

This experiment was designed to provide more information concerning ethanol's effects on female sexual behavior and the antagonism of those effects by naloxone. This experiment tests whether the reversal of ethanol's effects by naloxone is dependent on the dose of naloxone.

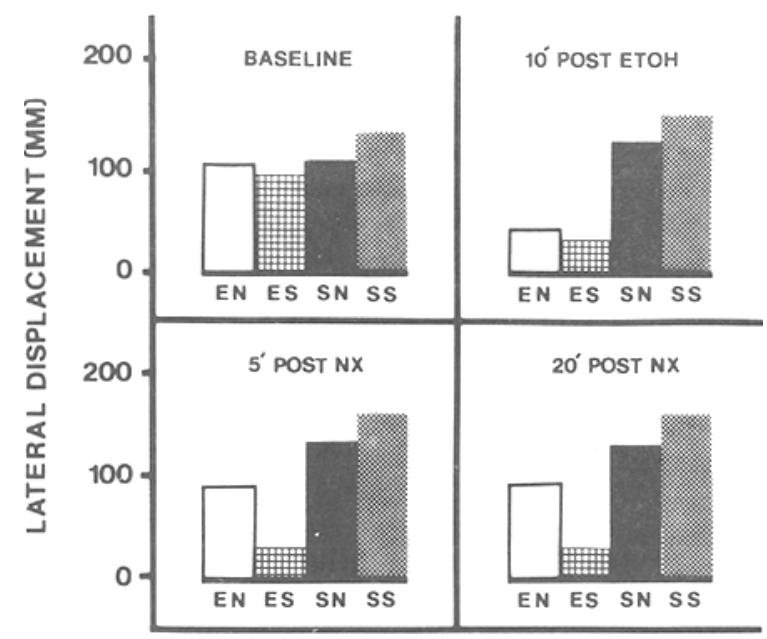

Figure 1. Naloxone antagonism of ethanol's inhibition of female sexual behavior.

\section{Method}

Subjects. The subjects were 35, adult, drug-naive, female golden hamsters (Mesocricetus auratus) purchased from Engle Laboratory Animals, Inc., Farmersburg, Indiana, weighing 90-100 g at the beginning of the procedures. The subjects were housed as the subjects in Experiment 1 were. Ovariectomies were completed using the same surgical procedure as in Experiment 1. Sexually active male hamsters were used as stimulus males throughout the procedures.

Design and Procedure. The subjects were tested for sexual behavior using the same single-blind behavioral testing paradigm as in Experiment 1. The subjects were assigned randomly (five per group) to one of the following conditions: (1) physiological saline administration $(15 \mathrm{ml} / \mathrm{kg})$ followed by physiological saline $(1.0 \mathrm{mg} / \mathrm{kg})$ administration, (2) physiological saline administration followed by naloxone hydrochloride administration $(8.0 \mathrm{mg} / \mathrm{kg}$ of a $10-\mathrm{mg} / \mathrm{ml}$ solution, (3) ethanol administration $(1.2 \mathrm{~g} / \mathrm{kg}$ in a $10 \%$ solution, $\mathrm{v} / \mathrm{v})$, followed by physiological saline administration, and (4) ethanol administration followed by naloxone hydrochloride administration $(.5,1.0,2.0$, or $8.0 \mathrm{mg} / \mathrm{kg}$ of a $10-\mathrm{mg} / \mathrm{ml}$ solution). All injections were given (sc) under the loose skin of the upper back and neck regions.

\section{Results}

Lordosis latency and lordosis duration. When the lordosis latency data were submitted to an overall repeated-measures ANOVA, the results indicated no reliable main effects or interactions. However, ethanol did increase lordosis duration $[\mathrm{F}(1,31)=4.72$, $\mathrm{p}<.038$ ]. No other main effects interactions were reliable sources of variance.

Lateral displacement. The lateral displacement data were analyzed in the following manner. First, an overall ANOVA across all groups and trials was performed. After a significant group $\times$ trial interaction was obtained $[\mathrm{F}(18,84)=11.07, \mathrm{p}<.001]$, analyses for simple main effects were computed separately for each trial. When the tests for simple main effects yielded significant group differences $(\alpha=.05)$, post hoc comparisons (Newman-Keuls) were performed to determine the significant differences among group means.

The baseline scores did not vary significantly among groups. Ten minutes after the administration of either ethanol or saline, the animals receiving ethanol had reliably lower scores than those receiving saline (ps < .05).

ANOVAs performed on the third and fourth trials ( 5 and 20 min after the administration of either naloxone or saline) indicated that the groups differed significantly on both trials [Trial $3, F(6,28)=4.06$, $\mathrm{p}<.005$, and Trial 4, $\mathrm{F}(6,28)=3.77, \mathrm{p}<.007]$. The control groups (those receiving saline and salinenaloxone) and the ethanol-naloxone groups had significantly greater lateral displacement scores than the group receiving ethanol followed by saline in both Trials 3 and 4 . There were also no other significant differences.

When an ANOVA was performed, using the average scores of the subjects across the last two trials, the factor associated with groups emerged as a reliable source of variance $[F(4,20)=11.17, p<.001]$, suggesting that ethanol's lowering of lateral displace- 


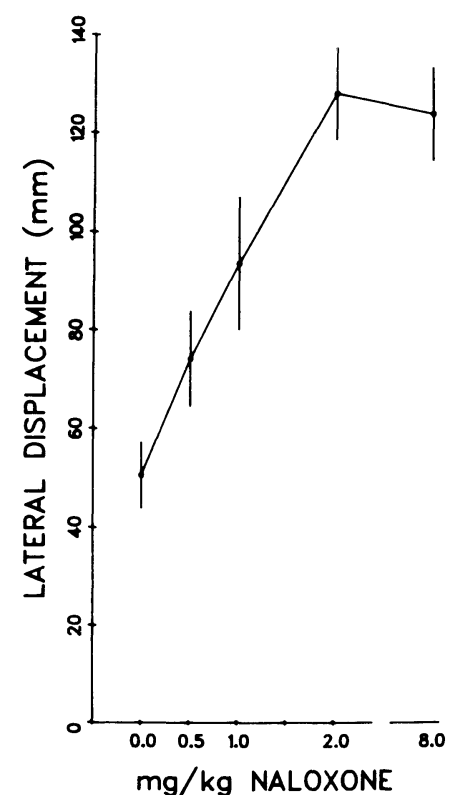

Figure 2. Naloxone $(.5,1.0,2.0$, and $8.0 \mathrm{mg} / \mathrm{kg}$ ) reversed ethanol-produced reductions in lateral displacement in a doserelated fashion.

ment was reversed by naloxone in a dose-related manner (see Figure 2). Animals receiving $1.0 \mathrm{mg} / \mathrm{kg}$ naloxone had significantly higher lateral displacement scores than animals receiving $0.0 \mathrm{mg} / \mathrm{kg}$ naloxone. Animals receiving $1.0,2.0$, or $8.0 \mathrm{mg} / \mathrm{kg}$ naloxone were not reliably different from each other; however, the scores of animals receiving 2.0 and $8.0 \mathrm{mg} / \mathrm{kg}$ naloxone were significantly higher than the scores of animals receiving either 0.0 or $0.5 \mathrm{mg}$ / $\mathrm{kg}$ naloxone $(\mathrm{ps}<.05)$.

\section{Discussion}

The results of this experiment indicate that ethanol suppresses some aspects of female sexual behavior (lordosis duration and lateral displacement) and not others (lordosis latency). The effect of ethanol on the lordosis duration was not modified by naloxone. Naloxone did, however, reverse ethanol's effect on lateral displacement in a dose-related fashion.

\section{GENERAL DISCUSSION}

The opiate antagonist naloxone reverses the effects of ethanol on one measure of sexual behavior in the female hamster (lateral displacement) in a doserelated fashion. Lordosis latency and lordosis duration were not consistently affected by ethanol, although ethanol did tend to increase both lordosis latency and lordosis duration.

In 1970, two laboratories independently demonstrated that subsequent to ethanol intake tetrahydroisoquinoline compounds (TIQS) are formed (Cohen \& Collins, 1970; Davis \& Walsh, 1970). Subsequent research has demonstrated that these compounds exhibit stereospecific binding properties on opiate receptors (Britton, Ravier, Shier, Bloom, \& Vale, 1979; Greenwald, Fertel, Wong, Schwartz, \& Bianchine, 1979). This binding was shown to be reversed by the opiate antagonist naloxone (Greenwald et al., 1979). Behavioral tests have shown that acute administration of these compounds produces analgesia similar to that produced by morphine, and this TIQproduced analgesia is antagonized by naloxone (Greenwald et al., 1979). These findings lead to the controversial suggestion that TIQs have pharmacological associations with the endogenous opioid system. The results reported here indicate that some of ethanol's effects on female sexual behavior may be achieved through endorphin release or through the formation of opiate-line compounds (TIQs) which interact with the opiate receptors.

\section{REFERENCES}

Altshule r, H. L., Phillips, P., \& Feinhandler, D. A. Alteration of ethanol self-administration by naloxone. Life Sciences, $1980,26,679-688$.

Belluzzi, J. D., \& STEin, L. Enkephalin may mediate euphoria and drive reduction reward. Nature, 1977, 266, 556-558.

Britton, D. R., Ravier, C., Shier, T., Bloom, F., \& Vale, W. Dopamine antagonist activity of tetrahydroisoquinolines. Abstracts for the Society of Neurosciences, 1979, 5, 439.

Cohen, G., \& Collins, M. A. Alkaloids from catecholamines in adrenal tissue: Possible role in alcoholism. Science, 1970, 167, 1749-1751.

Davis, V. E., \& Walsh, M. D. Alcohol, amines and alkaloids: A possible basis for alcohol addiction. Science, 1970, 167, 1005-1007.

Greenwald, J. E., Fertel, R. H., Wong, L. K., Schwartz, R. D., \& BiANChine, J. R. Salsolinol and tetrahydropapaveroline bind to opiate receptors in the rat brain. Federation Proceedings 63rd Annual Meeting, 1979, 38, 379. (Abstract)

HetTA, J. Effects of morphine and naltrexone on sexual behavior of the female rat, Acta Physiologica Scandinavica, 1976, 440 (Suppl.), No. 155.

Lorens, S. A., \& Sianti, S. M. Naloxone blocks the excitatory effects of ethanol and chlordiazepoxide on lateral hypothalamic self-stimulation behavior. Life Sciences, 1979, 23, 1359-1364.

Mackenzie, A. I. Naloxone in alcohol intoxication. Lancet, 1979, 733-734.

Noble, R. G. Mounting in female hamsters: Effects of different hormone regimes. Physiology \& Behavior, 1977, 19, 519-526.

Noble, R. G. The sexual reflexes of the female hamster: A descriptive analysis. Physiology \& Behavior, 1979, 23, 1001-1005.

Ostrowski, N. L., Stapleton, J. M., Noble, R. G., \& Reid, L. D. Morphine and naloxone's effects on sexual behavior of the female golden hamster. Pharmacology, Biochemistry and Behavior, 1979, 11, 673-681.

Sorensen, S. C., \& MAtTison, K. Naloxone as an antagonist in severe alcohol intoxication. Lancet, 1978, 688-689.

Stapleton, J. M., Merriman, V. J., Coogle, C. L., Gelbard, S. D., \& REID, L. D. Naloxone reduces pressing for intracranial stimulation of sites in the periaqueductal gray area, accumbens nucleus, substantia nigra, and lateral hypothalamus. Physiological Psychology, 1979, 7, 427-436.

(Manuscript received May 29, 1981; revision accepted for publication October 29,1981 .) 